\title{
The Role of Atom Shadow on Sorbitol Molecules to Heal Diabetic Diseases
}

\author{
MINTO SUPENO* and AGUNG PRATAMA \\ Department of Chemistry, Faculty of Mathematics and Natural Sciences, Universitas \\ Sumatera Utara, Jl. Bioteknologi No.1, Kampus USU, Medan 20155, Indonesia. \\ *Corresponding author E-mail: mintosupeno09@gmail.com
}

http://dx.doi.org/10.13005/ojc/370614

(Received: October 19, 2021; Accepted: November 20, 2021)

\begin{abstract}
Sorbitol has a low calorie value, this is due to the presence of a pair of $\mathrm{O}-\mathrm{H}$ free electrons on the sorbitol molecule. The pair of free electrons can be removed by the Tunnel method (through the shadow of the sorbitol container). Sorbitol which has lost a pair of free electrons from the O-H group is called sorbitol switching. The instrument used to prove the release of a pair of free electrons in the $\mathrm{O}-\mathrm{H}$ group is to use FTIR and clinical trials conducted on mice given sorbitol to prove the effectiveness between sorbitol and sorbitol switching. The results show that sorbitol switching is able to maintain the stability of blood sugar levels in the body of mice and can reduce blood sugar levels.
\end{abstract}

Keywords: Sorbitol, Sorbitol Switching, Blood Sugar, Tunnel Method.

\section{INTRODUCTION}

The consumption of sucrose as a food sweetener is now being replaced and reduced by its use. Sugar substitutes must meet the requirements, namely that they must have a sweet taste, are not toxic, are not expensive, cannot be shared by dental plaque bacteria, have calories, besides that they must also be able to be done industrially. Of all these requirements, a good sugar substitute is derived from the sugar alcohol group 1 . Sorbitol $\left(\mathrm{C}_{6} \mathrm{H}_{14} \mathrm{O}_{6}\right)$ comes from the sugar alcohol group. Sugar alcohol is the result of reduction of glucose in which all the oxygen atoms in a simple sugar alcohol molecule are present in the form of a hydroxyl group, synonymous with polyhydric alcohol (polyols) ${ }^{2}$. Polyols can be divided into two, namely acyclic polyols and cyclic polyols. Sorbitol belongs to the acyclic polyols group with six carbon chains ${ }^{3}$ and has the advantage, among others, that it is not cariogenic ${ }^{4}$.

Sorbitol is included in the unique sugar alcohol group, namely sugar alcohols do not have a carbonyl group in the chain. This fact makes sugar alcohols less chemically reactive than sugars which have aldose and ketose bonds and thus participate less in the formation of acids in dental plaque ${ }^{5,10}$. Sorbitol is a glucose-derived sugar alcohol or polyol sweetener. This sweetener is water soluble and is found in many fruits and vegetables ${ }^{6,9}$. Sorbitol

This is an Open Access article licensed under a Creative Commons license: Attribution 4.0 International (CC- BY). Published by Oriental Scientific Publishing Company @ 2018

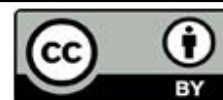


is a low calorie sweetener. When compared to sugar, sorbitol has 35\% lower calories. One gram of sugar provides 4 calories.Meanwhile, one gram of sorbitol provides only 2.6 calories. Because of its low calorie content, sorbitol is often incorporated into multi-industrial products, including pharmaceutical products, sugar-free processed foods, and oral health products. These sweeteners are also added to processed products to add flavor, improve texture and retain moisture ${ }^{7,8}$.

Sorbitol can be used as a substitute for sucrose in people with diabetes. The caloric value of foods containing sorbitol is as high as sugar, but the sweetness is only about 60 percent of the sweetness of sucrose. The disadvantage of sorbitol is that when used in excessive amounts it can cause diarrhea. Sorbitol is a sugar that is absorbed very little by the small intestine, so that sorbitol will enter the large intestine directly and can support diarrhea and flatulence ${ }^{11}$. Sorbitol is quite safe to use as a sugar substitute in people with diabetes mellitus, because its absorption is slower than glucose. This slow absorption will automatically reduce the degree of drastic increase in blood glucose and insulin response. Low calories are also in accordance with the target of weight control in diabetes mellitus patients. For this purpose sorbitol is widely used to make low-calorie food products such as sugar-free candy, chewing gum (usually mint flavor), confectionery industry, bread and chocolate sweeteners, and frozen food sweeteners ${ }^{12}$.

The atoms in a molecule have a shadow (soul). The nature of the true atom and its shadow can show different physical and chemical properties. We can see this phenomenon from the XRD analysis of graphene which shows different crystallinity ${ }^{15}$. Therefore, in this paper, we conducted a study to prove the phenomenon of soul atoms and their application in lowering blood sugar levels by comparing the effectiveness of true sorbitol with shadow sorbitol.

\section{EXPERIMENTAL}

\section{Materials and Instrumentations}

The materials used in this study were kerosene, sorbitol, charcoal. FT-IR analysis using a Shimadzu IR Prestige-21 and clinical testing of blood sugar levels in mice using a glucometer measuring strips.

\section{Methods}

$250 \mathrm{~mL}$ of sorbitol, put into plastic containers that have been cleaned, then pour the kerosene into a glass plate. Put the plastic containers containing sorbitol on a glass plate that has been filled with kerosene and place the charcoal on the bottom of a wooden cabinet that has a neon lamp inside. Turn on the fluorescent lights, and let the exposure occur for seven days in a closed state. After seven days, sorbitol switching is obtained which will be analyzed by FTIR and clinical test on mice.

\section{RESULTS AND DISCUSSION}

\section{FTIR Analysis}

Sorbitol switching is produced due to the irradiation of fluorescent lamps which makes the sorbitol contained in the container produces a shadow which will be absorbed by the adsorbent, the charcoal found at the bottom of the wooden cabinet. The irradiation produces shadows, and causes the release of free electrons in the $\mathrm{O}-\mathrm{H}$ group on sorbitol. The release of free electrons in the sorbitol molecule is called sorbitol switching. The evidence that shows that the sorbitol molecule has released a pair of electrons from the $\mathrm{O}-\mathrm{H}$ group can be seen from the difference in the FTIR spectrum shown in Figure 1.

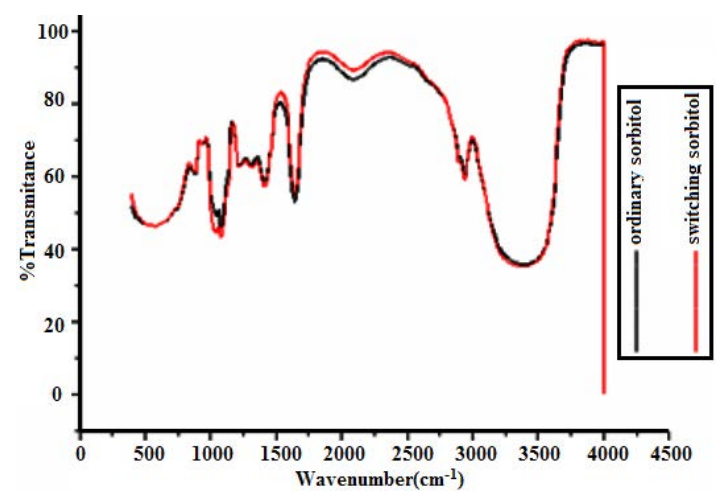

Fig. 1. FTIR spectrum sorbitol and sorbitol switching

In Fig. 1, there is a difference in \% T absorbed by the sorbitol and sorbitol switching molecules at a wavelength of $1408 \mathrm{~cm}^{-1}$. It can be seen that the \% $\%$ in the sorbitol molecule is $59 \%$ while in the sorbitol switching molecule is $57.5 \%$. This reduction in \% T could explain the indication of the release of a pair of free electrons from sorbitol. 
The intensity drops because a pair of free electrons in the $\mathrm{O}-\mathrm{H}$ group has been absorbed by the shadow of the atom.

\section{Clinical test for mice}

Clinical tests of sorbitol and sorbitol switching are performed on mice weighing about 135-160 $\mathrm{g}$ and blood sugar levels before being given alloxan is $89-101 \mathrm{mg} / \mathrm{dL}$ on the first day. Treatment of alloxan, sorbitol, and sorbitol switching as well as measurement of blood sugar levels before giving alloxan, sorbitol, and sorbitol switching can be seen in Figure 2.

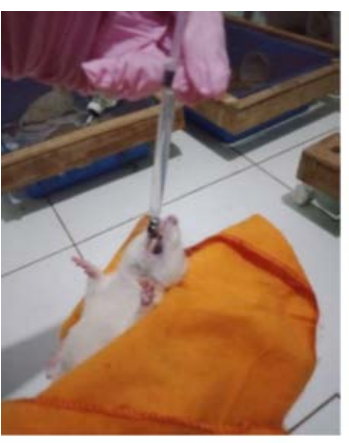

(a)

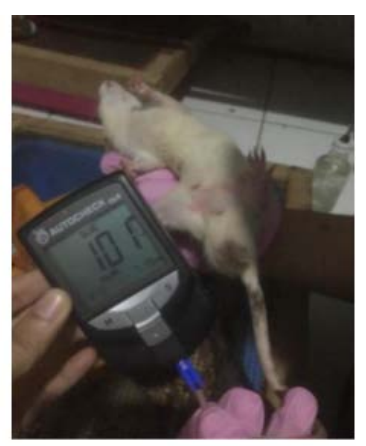

(b)
Fig. 2(a)Treatment of alloxan, sorbitol, and sorbitol switching (b)Measurement of blood sugar levels before giving alloxan, sorbitol, and sorbitol switching

While the measurement of blood sugar levels for the treatment of after giving alloxan, sorbitol and sorbitol switching can be seen in Figure 3

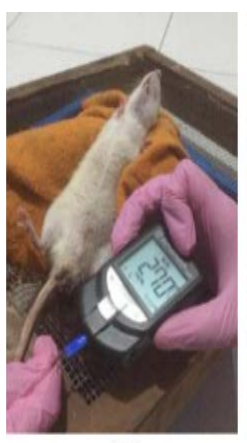

(a)

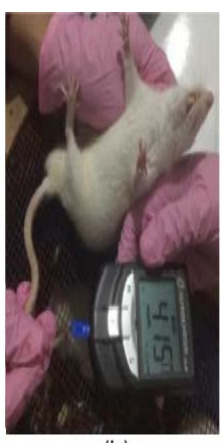

(b)

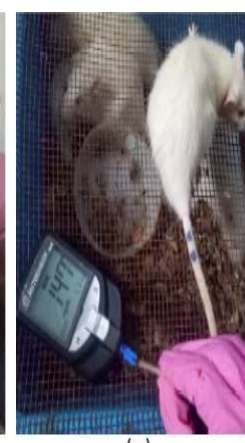

(c)
Fig. 3Measurement of blood sugar levels

(a) after the treatment of alloxan

(b)after the treatment of sorbitol

(c)after the treatment of sorbitol switching

Data on the measurement of blood sugar levels in twenty samples of mice can be seen in the graph shown in Figures 4 to 7.
From Fig. 4, it can be seen that the mice that had not been given alloxan showed a relatively stable average blood sugar level and fluctuated from the first day to the last day of observation, with an average blood sugar level of $107 \mathrm{mg} / \mathrm{dL}$. Whereas in Fig. 5, when the mice were treated with alloxan, there was a spike in blood sugar increases from the first day to the second day and was relatively stable on the third to the last day of observation with an average blood sugar level of $231 \mathrm{mg} / \mathrm{dL}$ and a decrease in blood sugar levels the average from the second day to the eighteenth day was $8 \%$.

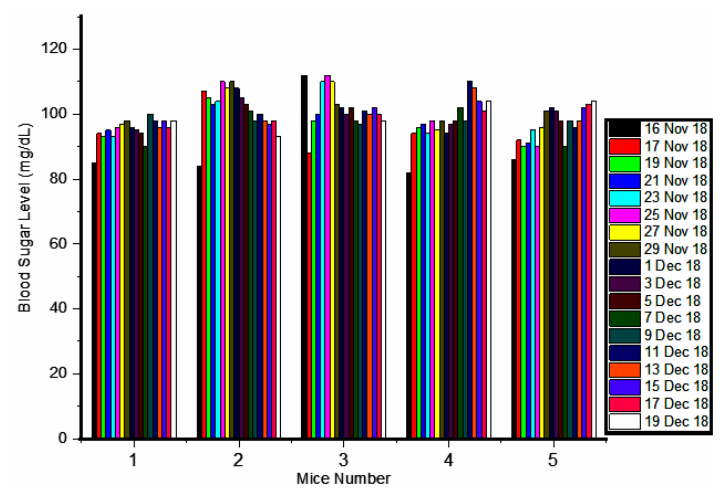

Fig. 4. Graphic measurement of blood sugar levels to mice before being given alloxan treatment

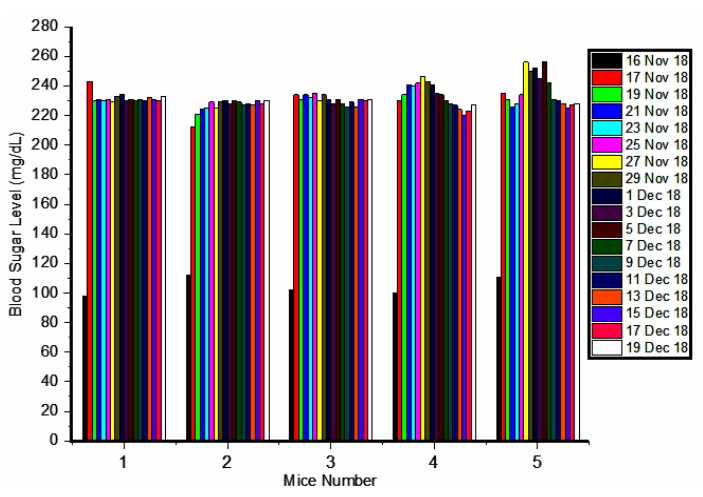

Fig. 5. Graphic measurement of blood sugar levels to mice after being given alloxan treatment

Alloxan treatment has an effect on the degradation of $\beta$ cells on the islets of Langerhans, which is the organ responsible for making insulin in the body. Several hypotheses about the mechanism of action of alloxan as a diabetogen include the mechanism of chelating against $Z n$ and affecting $\beta$ cell enzymes so that amino acid deamination and decarboxylation occur. Research on the mechanism of action of alloxan In vitro shows that alloxan induces 
the release of calcium ions from the mitochondria which results in disrupted cell oxidation processes ${ }^{13}$. The release of calcium ions from the mitochondria results in a disruption of homeostasis which is the

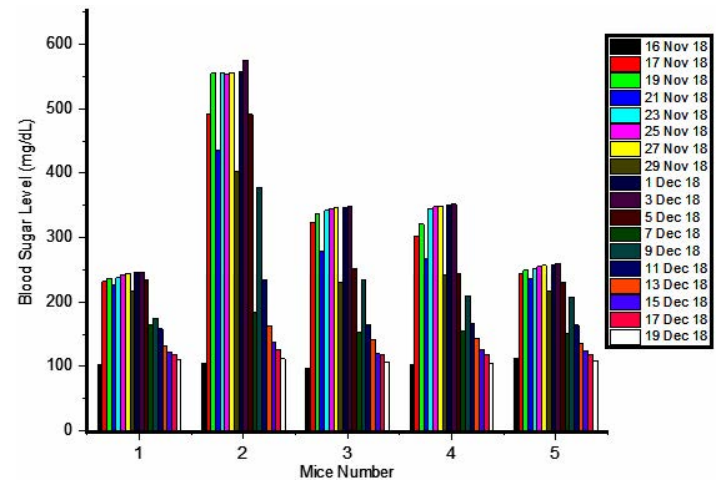

Fig. 6. Graphic measurement of blood sugar levels to mice after being given sorbitol treatment

Figure 6 is a graph showing the treatment of mice treated with sorbitol. The spike in the increase in blood sugar occurred on the first day to the tenth day reaching the highest peak with blood sugar levels of 247 for each mouse; 575; 348; 352; 260 $\mathrm{mg} / \mathrm{dL}$. On the eleventh day, there was a decrease in blood sugar levels until the last day of observation and the average decrease was $70 \%$.

Meanwhile, Fig. 7 shows the treatment of mice given sorbitol switching. Similar to the treatment of sorbitol, sorbitol switching which was tested on mice raised blood sugar levels on the second to the tenth day, what was different was that sorbitol switching raised the average blood sugar level to a level of $307 \mathrm{mg} / \mathrm{dL}$, not too high compared to sorbitol. Decrease in average blood sugar levels with sorbitol switching treatment reached $74 \%$.

From Fig. 6 and 7 it can be seen that the treatment of sorbitol switching can maintain the stability of blood sugar levels and is more effective in reducing blood sugar levels than sorbitol. This is because the switching sorbitol which has lost a pair of electrons from the O-H group results in a reduced beginning of cell death. With the destruction of the $\beta$ cells of the islets of Langerhans, the body will lose insulin absolutely so it is very dependent on insulin from outside the body ${ }^{14}$.

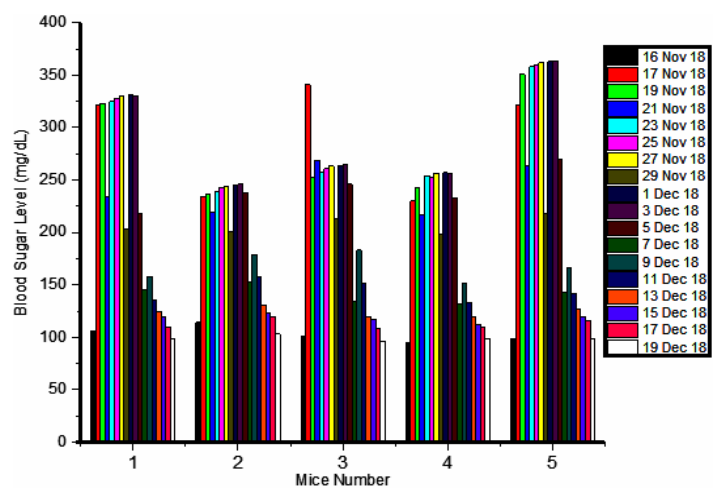

Fig. 7. Graphic measurement of blood sugar levels to mice after being given sorbitol switching treatment calorific value so that it can lower blood sugar levels compared to sorbitol and this also shows that sorbitol switching is an atomic image of the sorbitol molecule.

\section{CONCLUSION}

Based on the results of the research conducted, it can be concluded that sorbitol has lost free electrons adsorbed by atomic shadows, resulting in sorbitol switching. This can be proven from the decrease in \%T sorbitol switching in the FTIR analysis results. The results of clinical trials proved that sorbitol switching was able to maintain the stability of blood sugar levels and was able to reduce blood sugar levels in mice.

\section{ACKNOWLEDGMENT}

This research did not receive any specific grant from funding agencies in the public, commercial, or not-for-profit sectors.

\section{Conflict of interest}

The author declare that we have no conflict of interest.

\section{REFERENCES}

1. Grembecka, M. European Food Research and Technology., 2015, 241, 1-14.

2. Shankar, P.; Ahuja, S.; Sriram, K.; Nutrition., 2013, 29, 1293-1299.
3. Makinen, K. K. Med Princ Pract., 2011, 20, 303-320.

4. Ellwood, K.C. Am J Clin Nutr., 1995, 62, 1169-1174. 
5. Fitch, C.; Keim, K. S. JAcad Nutr Diet., 2012, 112, 739-758.

6. Lee, J. Food Chemistry., 2015, 166, 616-622.

7. Park, Y.C.; Oh, E.J.; Jo, J.H.; Jin, Y.S.; Seo, J.H. Curr. Opinion in Biotec., 2016, 37, 105-113.

8. Ortiz, M.E.; Bleckwedel, J.; Raya, R.R.; Mozzi, F. Appl Microbiol Biotechnol., 2013, 97, 4713-4726.

9. Barbieri, G.; Barone, C.; Bhagat, A.; Caruso, G.; Conley, Z.R.; Parisi, S. Springer International Publishing., 2014.

10. Ladero, V.; Ramos, A.; Wiersma, A.; Goffin, P.; Schanck, A.; Kleerebezem, M.; Hugenholtz, J.; Smid, E.J.; Hols, P. Appl Environ Microbiol.,
2007, 73, 1864-1872.

11. Yao C.K.; Tan, H.L.; van Langenberg, D.R.; Barrett, J.S.; Rose, R.; Liels, K.; Gibson, P.R.; Muir, J.G. J Hum Nutr Diet., 2014, 27(Suppl. 2), 263-275.

12. Silveira, M.M.; Jonas, R. Appl Microbiol Biotechnol., 2002, 59, 400-408.

13. Ikechukwu, C.F.E.; Obri, A.I. Nigerian journal of physiological sciences., 2009, 24(2), 153-155.

14. Edem, D.O. European Journal of Scientific Research., 2009, 33, 669-678.

15. Supeno, M.; Siburian, R. Journal of King Saud University-Science., 2020, 32, 189-190. 